\title{
Article \\ Effects of Fe-Ions Irradiation on the Microstructure and Mechanical Properties of FeCrAl-1.5wt.\% ZrC Alloys
}

\author{
Runzhong Wang ${ }^{1}$, Hui Wang ${ }^{2, *}$, Xiaohui Zhu ${ }^{1}$, Xue Liang ${ }^{3}$, Yuanfei Li ${ }^{4}$, Yunxia Gao ${ }^{5}$, Xuguang An ${ }^{6}$ \\ and Wenqing Liu ${ }^{1, *}$
}

check for updates

Citation: Wang, R.; Wang, H.; Zhu, X.; Liang, X.; Li, Y.; Gao, Y.; An, X.; Liu, W. Effects of Fe-Ions Irradiation on the Microstructure and Mechanical Properties of FeCrAl-1.5wt.\% ZrC Alloys. Nanomaterials 2021, 11, 3423. https://doi.org/10.3390/nano11123423

Academic Editor: Giancarlo Rizza

Received: 3 November 2021

Accepted: 14 December 2021

Published: 17 December 2021

Publisher's Note: MDPI stays neutral with regard to jurisdictional claims in published maps and institutional affiliations.
1 Institute of Materials, School of Materials Science and Engineering, Shanghai University, Shanghai 200444, China; wrzh1995shu@163.com (R.W.); ZXH21@shu.edu.cn (X.Z.)

2 Science and Technology on Reactor Fuel and Materials Laboratory, Nuclear Power Institute of China, Chengdu 610041, China

Key Laboratory for Microstructures, Shanghai University, Shanghai 200444, China; liangxue@shu.edu.cn

4 Suzhou Nuclear Power Research Institute, Suzhou 215004, China; p193258@cgnpc.com.cn

5 Key Laboratory of Materials Physics, Institute of Solid State Physics, Chinese Academy of Sciences, Hefei 230031, China; yxgao@issp.ac.cn

6 School of Mechanical Engineering, Chengdu University, Chengdu 610106, China; anxuguang@cdu.edu.cn

* Correspondence: qinghe5525@163.com (H.W.); wqliu@staff.shu.edu.cn (W.L.)

\begin{abstract}
Fe-13Cr-3.5Al-2.0Mo-1.5wt.\% ZrC alloy was irradiated by $400 \mathrm{keV} \mathrm{Fe}^{+}$at $400{ }^{\circ} \mathrm{C}$ at different doses ranging from $6.35 \times 10^{14}$ to $1.27 \times 10^{16}$ ions $/ \mathrm{cm}^{2}$ with a corresponding damage of 1.0-20.0 dpa, respectively, to investigate the effects of different radiation doses on the hardness and microstructure of the reinforced $\mathrm{FeCrAl}$ alloys in detail by nanoindentation, transmission electron microscopy (TEM), and atom probe tomography (APT). The results show that the hardness at 1.0 dpa increases from 5.68 to $6.81 \mathrm{GPa}$, which is $19.9 \%$ higher than a non-irradiated specimen. With an increase in dose from 1.0 to $20.0 \mathrm{dpa}$, the hardness increases from 6.81 to $8.01 \mathrm{GPa}$, which is an increase of only $17.6 \%$, indicating that the hardness has reached saturation. TEM and APT results show that high-density nano-precipitates and low-density dislocation loops forme in the $1.0 \mathrm{dpa}$ region, compared to the non-irradiated region. Compared with 1.0 dpa region, the density and size of nano-precipitates in the 20.0 dpa region have no significant change, while the density of dislocation loops increases. Irradiation results in a decrease of molybdenum and carbon in the strengthening precipitates $(\mathrm{Zr}$, $\mathrm{Mo})(\mathrm{C}, \mathrm{N})$, and the proportionate decrease of molybdenum and carbon is more obvious with the increase in damage.
\end{abstract}

Keywords: $\mathrm{FeCrAl}$; irradiation damage; $\mathrm{ZrC}$; nanoindentation; atom probe tomography

\section{Introduction}

Cladding materials, as the first barrier for a reactor, have to withstand the high temperature, high pressure, and strong irradiation and corrosion of high-temperature steam. The traditional zircaloy cladding can react violently with steam under high pressure and temperature, and release large amounts of hydrogen and heat, causing a severe hydrogen explosion, which is the main reason for the Fukushima nuclear accident [1-6]. There is an urgent need to develop other cladding materials with better performance. FeCrAl alloy, which has no risk of causing a hydrogen explosion, is considered to be a promising candidate for advanced reactor accident-resistant cladding because of its excellent resistance to corrosion and oxidation in high-temperature steam [7].

The researchers have improved the properties of FeCrAl alloy by optimizing the composition, determining its range to be within Fe-(10 14) Cr-(3 5) Al [8-12]. Nevertheless, the disadvantage posed by the poor radiation resistance of $\mathrm{FeCrAl}$ alloy cannot be solved by optimizing its composition [13-15]. It has been found that introducing nano-sized oxide, carbide, or nitride particles could effectively refine the grains and optimize the grain 
boundaries of the alloy $[16,17]$. Moreover, these dispersed nano-precipitates can be sinks for absorbing the interstitials and vacancies induced by irradiation [18]. All of these factors increase the irradiation resistance for $\mathrm{FeCrAl}$ alloys as cladding.

Past research about nano-precipitate-dispersion-strengthened $\mathrm{FeCrAl}$ alloys has mainly focused on FeCrAl- $\mathrm{Y}_{2} \mathrm{O}_{3}$. However, due to the high aluminum content in $\mathrm{FeCrAl}$ alloy and the strong affinity between yttrium and aluminum, a large number of large-size Y-Al-O is generated, which deteriorates the properties of the material. [19-21]. $\mathrm{ZrC}$ possesses high chemical stability, shows a high melting point $\left(\sim 3540^{\circ} \mathrm{C}\right)$, and does not react with $\mathrm{Al}$, which can effectively avoid the formation of coarse particles. In addition, $\mathrm{ZrC}$ obtains a much lower thermal neutron absorption cross-section than $\mathrm{Y}_{2} \mathrm{O}_{3}$ [22]. Therefore, compared with $\mathrm{Y}_{2} \mathrm{O}_{3}, \mathrm{ZrC}$ is more ideal for reinforcement of $\mathrm{FeCrAl}$ alloys. Wang et al. prepared $\mathrm{ZrC}$-reinforced $\mathrm{FeCrAl}$ alloys and found that the grains are significantly refined and higher temperature strengths are significantly enhanced compared to the pristine $\mathrm{FeCrAl}$ alloy [23]. Wan et al. also found that high tensile strength, large elongation at room temperatures, and high temperatures can be obtained for the FeCrAl alloy with $0.6 \mathrm{wt} . \% \mathrm{ZrC}$ [24].

The irradiation performance of the FeCrAl-1.0wt.\% ZrC alloy has been studied [22]. It is worth noting that Fe-ions irradiation induces the formation of a large amount of fine secondary phase, such as MoC particles and $\alpha^{\prime}$ phase. These particles will significantly improve the hardness of the material. Based on the above background, the irradiation properties of the $\mathrm{ZrC}$-reinforced $\mathrm{FeCrAl}$ alloys, depending on the dose of Fe-ions irradiation, are further investigated by nanoindentation, TEM, and APT techniques in this paper. The effects of different doses of Fe-ions irradiation on the mechanical properties and microstructures of the reinforced $\mathrm{FeCrAl}$ alloys are discussed in detail.

\section{Experimental Procedures}

Fe-13-Cr-3.5Al-2.0Mo-1.5 wt.\% ZrC alloy was selected as the irradiation experiment specimen in the present work. Fe-ions irradiation was conducted with $400 \mathrm{keV}$ Fe ions up to a dose of $6.35 \times 10^{14} \mathrm{Fe}^{+} / \mathrm{cm}^{2}$ (peak irradiation dose is $1.0 \mathrm{dpa}$ ) and $1.27 \times 10^{16} \mathrm{Fe}^{+} / \mathrm{cm}^{2}$ (peak irradiation dose is $20.0 \mathrm{dpa}$ ) at $400{ }^{\circ} \mathrm{C}$, respectively. The irradiation dose rate is $1.0 \times 10^{12} \mathrm{Fe}^{+} / \mathrm{cm}^{2} \cdot \mathrm{s}$ and the temperature of the specimen was controlled at $400{ }^{\circ} \mathrm{C}$ during the whole process.

The nanoindentation tests were conducted using Nano Indenter G200 (KLA Inc., Milpitas, CA, USA). The average hardness was obtained from 10 indentations with a $5 \times 2$ array and two points with large error are excluded for each specimen. The interval between the two test points was $30 \mu \mathrm{m}$ to avoid any overlap with the deformation region below each indentation and the limit of indentation depth was $300 \mathrm{~nm}$. Other parameters are given as follows: surface approach velocity was $10 \mathrm{~nm} / \mathrm{s}$, harmonic displacement target was $2 \mathrm{~nm}$, frequency target was $45 \mathrm{~Hz}$, poisons ratio was 0.3 , and temperature was $20^{\circ} \mathrm{C}$.

A double-beam focused ion beam method (FIB, Helios 600 Nanolab, FEI HONGKONG Co., Ltd., CZ) was utilized to prepare the specimens for transmission electron microscopy (TEM) and atom probe tomography (APT) measurements. The details of TEM and APT specimen preparation using FIB are the same as those in Refs. [25,26].

The microstructure of the irradiated specimen was observed with a JEOL 2100F field emission gun (FEG) TEM (JEOL LTD, Tokyo, Japan) and images were captured and analyzed by Gatan digital micrograph microscopy suite software (3.20.1314.0, Gatan Inc., Pleasanton, CA, USA).

The APT analyses were performed on a LEAP-4000X HR (CAMEMA, Madison, WI, USA) at a temperature of $50 \mathrm{~K}$ in the laser mode with an energy of $60 \mathrm{pJ}$ in a vacuum of $\sim 10^{-9} \mathrm{~Pa}$. Reconstruction and analyses were carried out utilizing IVAS 3.6.8 software (CAMEMA, Madison, WI, USA). Field evaporation and detector efficiency were set to $27 \mathrm{~V} \cdot \mathrm{mm}^{-1}$ and 0.37 , respectively. The strengthening precipitate in this alloy is a nitrogencombining carbide of niobium plus molybdenum, namely, $(\mathrm{Zr}, \mathrm{Mo})(\mathrm{C}, \mathrm{N})$. The 1.0 at.\% Zr iso-concentration surfaces was obtained to highlight the $(\mathrm{Zr}, \mathrm{Mo})(\mathrm{C}, \mathrm{N})$. In addition, the 
precipitates induced by irradiation are MoC and $\alpha^{\prime}$ phase, and we used 1.5 at. $\%$ Mo and 27 at $\% \mathrm{Cr}$ iso-concentration surfaces, respectively, to define them.

The identification and characterization of $(\mathrm{Zr}, \mathrm{Mo})(\mathrm{C}, \mathrm{N})$ precipitates, MoC, and $\alpha^{\prime}$ phase, which will be mentioned later, were undertaken by the maximum separation method with maximum separation distance $\left(d_{\max }\right)$ and minimum solute atom number $\left(N_{\min }\right)$. The $d_{\max }, N_{\min }$, and other relevant parameters of different precipitates are shown in Table 1. The determination and calibration of all these parameters listed in Table 1 are given in the Appendix A.

Table 1. The relevant parameters of different precipitates for "Cluster Analysis" in IVAS 3.6.8 software.

\begin{tabular}{cccccc}
\hline Precipitate & $d_{\max } / \mathbf{n m}$ & $N_{\min }$ /ions & Order/ions & $L / \mathbf{n m}$ & $d_{\text {erosion }} / \mathbf{n m}$ \\
\hline (Zr, Mo) (C, N)-unirr. & 3.2 & 50 & 1 & 3.2 & 3.2 \\
(Zr, Mo) (C, N)-irr. & 2.6 & 45 & 1 & 2.6 & 2.6 \\
MoC & 1.6 & 40 & 1 & 1.6 & 1.6 \\
$\alpha^{\prime}$ phase & 0.7 & 12 & 1 & 0.7 & 0.7 \\
\hline
\end{tabular}

\section{Results and Discussion}

\subsection{SRIM Simulation}

Figure 1 shows the profiles of damage and implantation which were predicted by SRIM (Stopping and Ranges of Ions in Matter) for the specimen after $400 \mathrm{keV}$ Fe-ions irradiation. The maximum damage and implantation are located around a depth of $80 \mathrm{~nm}$ and $150 \mathrm{~nm}$ from the irradiated surface, respectively. In addition, both decrease to zero at a depth of $360 \mathrm{~nm}$ after reaching the corresponding peak. Under the two different irradiation doses, the maximum displacement damage is $1.0 \mathrm{dpa}\left(6.35 \times 10^{14} \mathrm{Fe}^{+} / \mathrm{cm}^{2}\right)$ and $20.0 \mathrm{dpa}$ $\left(1.27 \times 10^{16} \mathrm{Fe}^{+} / \mathrm{cm}^{2}\right)$, respectively.

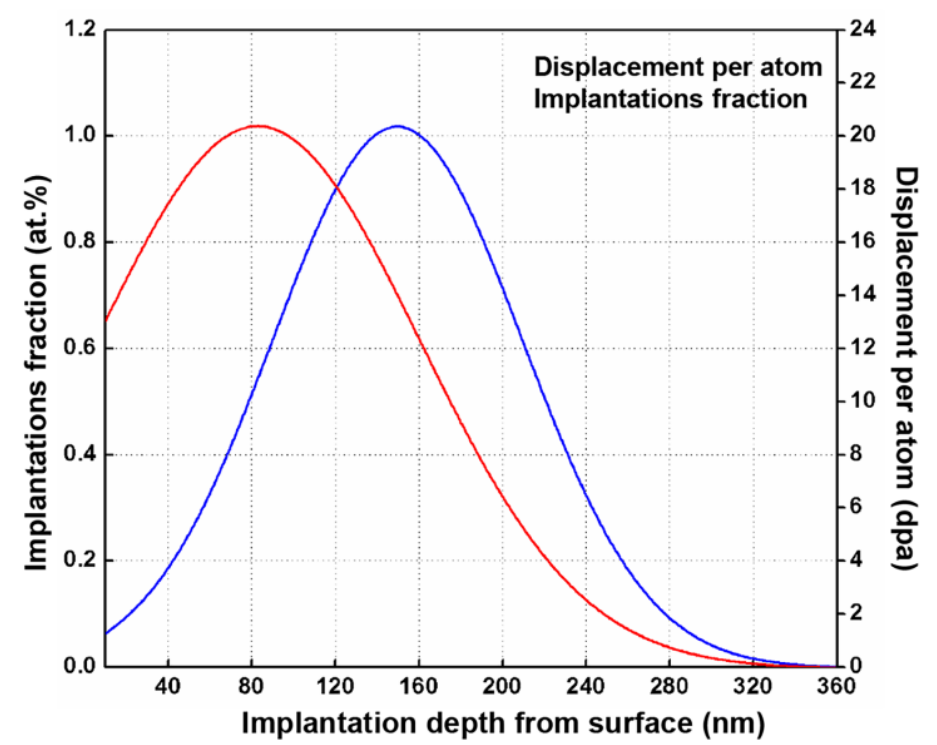

Figure 1. The profiles of damage (dpa) and implantation predicted by SRIM08 code. The red line indicates the change of dpa with indentation depth, and the blue line indicates the change of implantation fraction with indentation depth.

\subsection{Nanoindentation}

Figure 2 shows the profiles of average hardness with indentation depth, which were obtained from specimens at different irradiation doses by nanoindentation. Due to the existence of indentation size effects (ISE), softer substrate effects (SSE), and surface effects, the average hardness decreases with the increase in depth, as shown in Figure 2 [27]. 


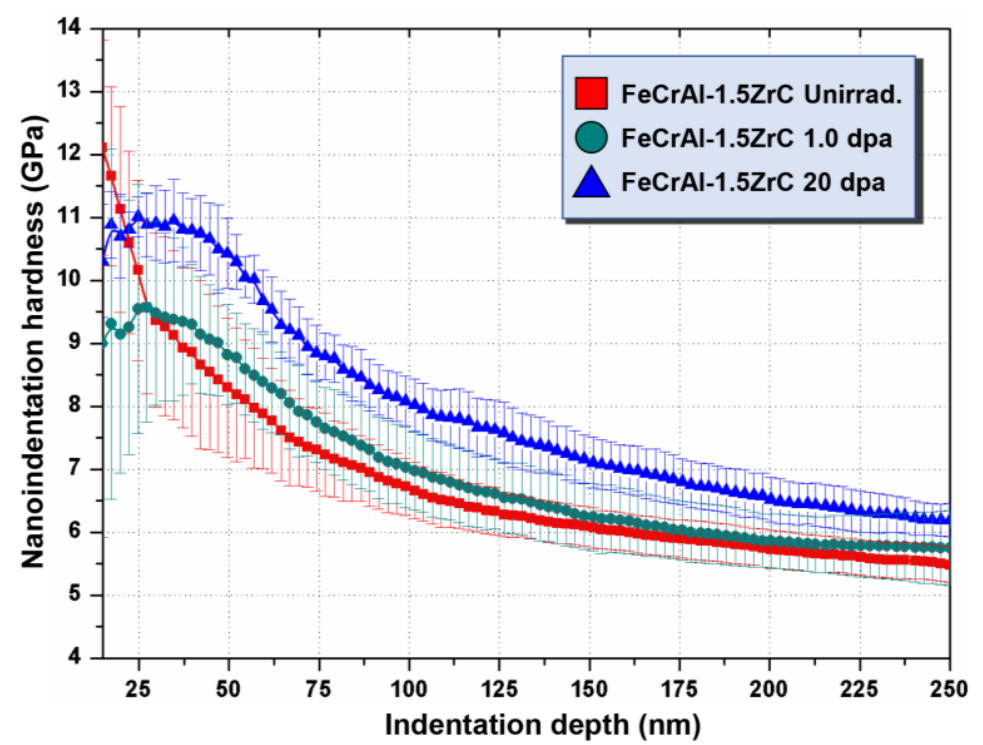

Figure 2. Curves of $H$ and $h$ for average nanoindentation hardness of specimens at different irradiation doses. The red line, green line and blue line represent the variation of hardness with indentation depth of unirradiated, $1.0 \mathrm{dpa}$ and $20 \mathrm{dpa}$ specimens, respectively.

The hardness is a comprehensive reflection of the hardness of the whole plastic influence zone. The radius of the plastic-affected zone is about $5 \sim 7$ times the indentation depth. Hence, if the press-in depth is beyond a certain value, the unirradiated region will begin to impact the hardness data; namely, the softer substrate effects (SSE) occur.

A model was proposed by Li [28] to explain the SSE. There is a transition point of SSE that appears at the critical depth $\left(h_{c}\right)$, which depends on the irradiation hardening value. Figure 3 shows a method to determine $h_{c}$ as proposed by Liu [29]. The ratios of $H_{\text {irr }} / H_{\text {unirr }}$ at the same depth were obtained and the peak ratios were located at a depth of about $50 \mathrm{~nm}$. A purple dashed arrow along the peak is used to represent the transition line. When the press-in depth beyond the depth value corresponds to transition line, the SSE starts to influence the accuracy of the measurement of hardness in the irradiated region. By this method, the critical indentation depth $h_{c}$ was determined to be about $50 \mathrm{~nm}$, which is about one-sixth of the damaged layer's thickness.

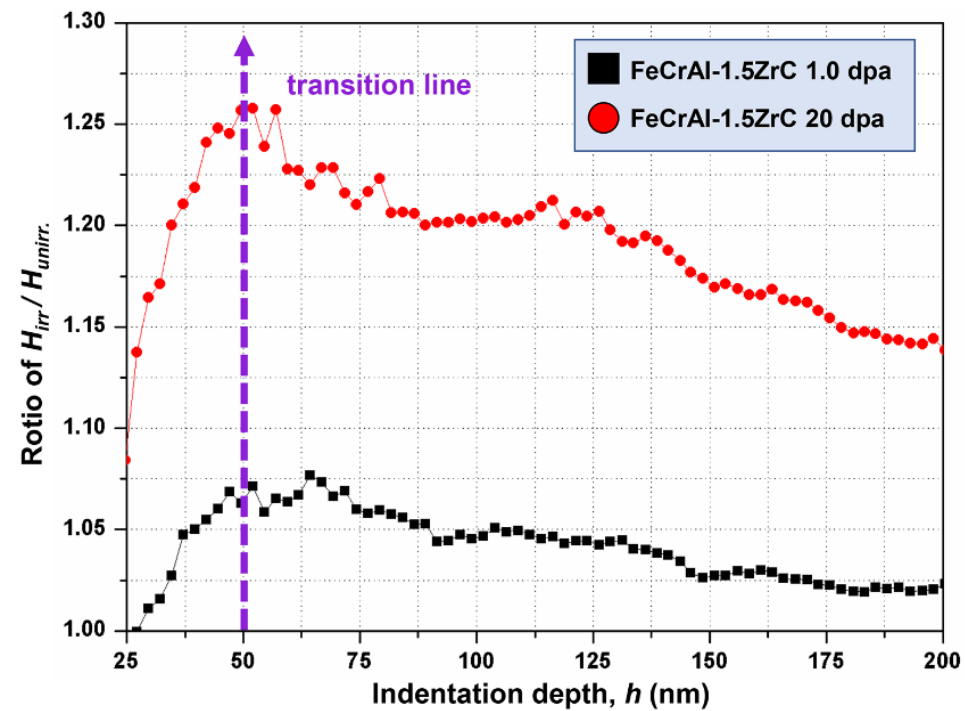

Figure 3. Dependence of the ratio of $H_{\text {irr }} / H_{\text {unirr }}$ on indentation depth at the irradiation doses of $1.0 \mathrm{dpa}$ and $20.0 \mathrm{dpa}$. 
In the shallow irradiation region, the indentation size effect (ISE) significantly affects the hardness measurement result [30-32]. For more accurate hardness, a formula was established by Nix and Gao to expounded the ISE based on the Geometrically Necessary Dislocation (GND), assuming that the indenter is of perfect rigidity and the material hardness is three times the yield strength [31]. The Nix-Gao model predicts the hardness depth profile as follows:

$$
\frac{H}{H_{0}}=\sqrt{1+\frac{h^{*}}{h}}
$$

where $H$ is the hardness for a given depth of indentation, $H_{0}$ is the hardness at infinite depth, $h^{*}$ is a characteristic length which depends on the material and the shape of the indenter tip, and $h$ is the depth of the press-in. Experimental data were re-plotted as $H^{2}$ vs. $1 / h$ in order to obtain the Nix and Gao parameter $H_{0}$, as shown in Figure 4.

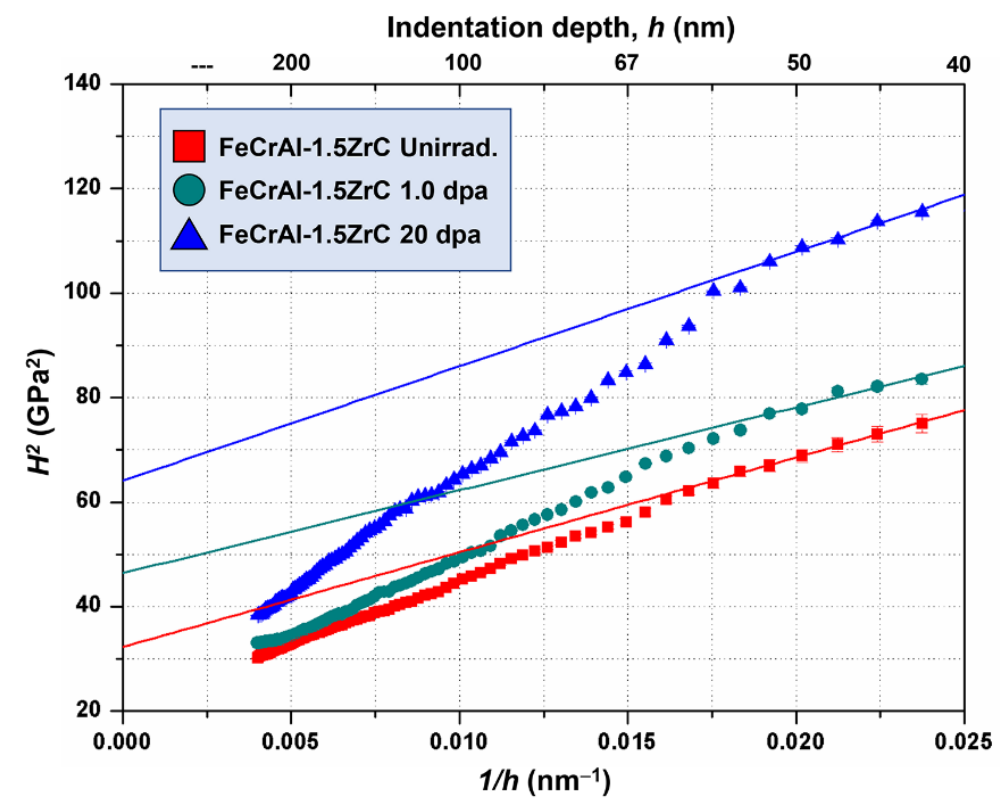

Figure 4. Profiles of $H^{2}$ and $h^{-1}$ for specimens at different irradiation doses. The red, green and blue lines represent unirradiated, $1.0 \mathrm{dpa}$ and $20 \mathrm{dpa}$ specimens, respectively.

It can be seen from Figure 4 that the profiles of the irradiated specimens at different doses show bilinearity and both shoulders are located at a depth of $\sim 60 \mathrm{~nm}$, which is almost consistent with the depth corresponding to the position of the transition line in Figure 3; namely, $h_{c}$. This is because, when the active area of the indenter reaches above the irradiation layer, the non-irradiated softer substrate affects the measurement of hardness. However, the data curve of the non-irradiated specimen shows a slight bilinearity with a shoulder depth of $\sim 70 \mathrm{~nm}$ as well, which is because of the significant surface effect in the shallow region $(<100 \mathrm{~nm})$ of the specimen. Therefore, assuming that the surface effect has the same effect on the specimens at different doses, the $H_{0}$ of the three specimens in the range of $40 \mathrm{~nm}<h<60 \mathrm{~nm}$ is calculated by the method proposed by Kasada [32] so as to minimize the effect of surface effect on the hardening irradiation measurement. The hardness and irradiation hardening increment $(\Delta H)$ of the three specimens are listed in Table 2, respectively, and the average hardness of specimens with damage is shown in Figure 5. 
Table 2. Calculated $H_{0}$ and $\Delta H$ based on the Nix-Gao model of specimens at different irradiation doses.

\begin{tabular}{ccc}
\hline Irradiation Dose & $\boldsymbol{H}_{\mathbf{0}} / \mathrm{GPa}$ & $\boldsymbol{\Delta} / \mathrm{GPa}$ \\
\hline $0 \mathrm{dpa}$ & 5.68 & 0 \\
$1.0 \mathrm{dpa}$ & 6.81 & 1.13 \\
$20 \mathrm{dpa}$ & 8.01 & 2.33 \\
\hline
\end{tabular}

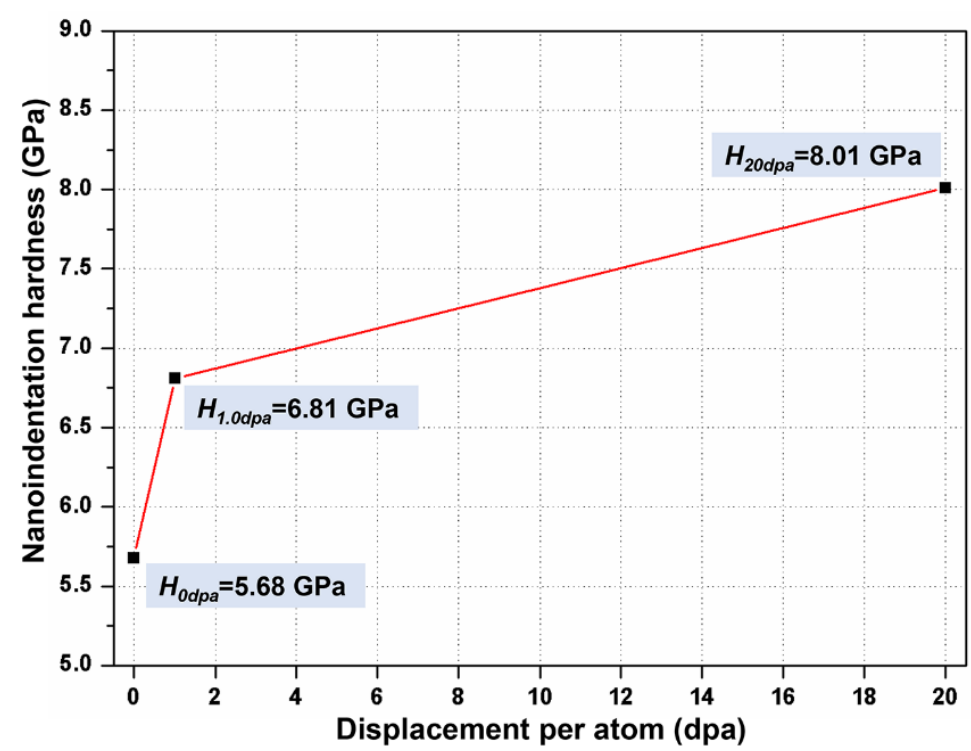

Figure 5. Plots of hardness $(H)$ vs. damage for specimens at different irradiation doses.

It can be found in Table 2, compared with the 5.68 GPa hardness of the non-irradiated specimen, the hardness of the $1.0 \mathrm{dpa}$ specimen increases to $6.81 \mathrm{GPa}$, which is about $19.9 \%$ higher than the non-irradiated specimen. The irradiation dose increases 20 times, from 1.0 to $20.0 \mathrm{dpa}$, and the hardness increases from 6.81 to $8.01 \mathrm{GPa}$, which is only an increase of $17.6 \%$. The increased rate of hardness in the 1.0 20.0 dpa progress is much lower than that in the $0 \sim 1.0 \mathrm{dpa}$ progress, indicating that, with the increase in damage, the irradiation hardening of the specimen tends toward saturation. This trend of saturation can be found more intuitively in Figure 5. It must be noted that Figure 5 does not express that there is a clear linear relationship between hardness and dpa, but illustrates that the increased rate of hardness decreases significantly with the increase in dpa. For example, comparing the slopes of two independent straight lines can obviously find this phenomenon.

\subsection{TEM}

TEM was performed to observe the microstructure of the damage region of the highdose irradiated specimen $\left(1.27 \times 10^{16} \mathrm{Fe}^{+} / \mathrm{cm}^{2}\right)$ and combined with the SRIM simulation results (Figure 6). It is shown that the contrast of the specimen rises with the increase in depth, the reason for which is the formation of a large number of dislocation loops induced by irradiation. At a depth of $80 \mathrm{~nm}$ from the surface, the contrast decreases after reaching the peak and there are almost no defects, such as dislocation loops, in the deeper region. The selected area electron diffraction (SAED) pattern in the internal of the specimen is displayed in the upper left corner of Figure 6. The diffraction pattern is single crystal diffraction spots, indicating that no amorphization occurred in the matrix of this specimen at the 20 dpa dose. 


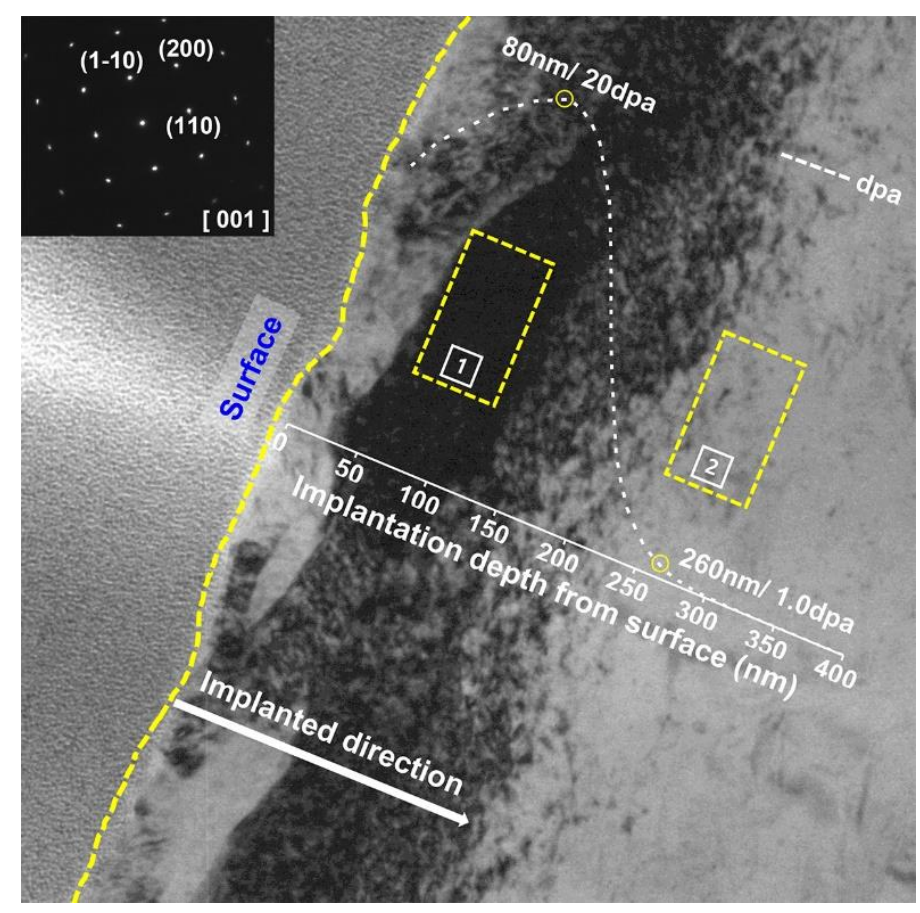

Figure 6. TEM images of the damage regions for the specimen irradiated with $400 \mathrm{keV}$ Fe-ions to $1.27 \times 10^{16} \mathrm{Fe} \mathrm{cm}^{-2}$ overlaid with the predicted dpa profile by SRIM. Region 1 in the figure is a high damage region and region 2 is a low damage region. The insert figure in the upper left corner is diffraction pattern of matrix.

According to the SRIM results, damage of the sample irradiated to a high dose is $20.0 \mathrm{dpa}$ at $\sim 80 \mathrm{~nm}$ and $1.0 \mathrm{dpa}$ at $\sim 260 \mathrm{~nm}$ from the sample surface. Therefore, the observation of microstructure could be conducted in the low damage region (region 1) and high damage region (region 2) in a single specimen The damage levels at the centers of region 1 and region 2 are about $20 \mathrm{dpa}$ and $1 \mathrm{dpa}$, respectively.

\section{4. $A P T$}

Figure 7 shows the results of atom distribution maps and iso-concentration surfaces of $\mathrm{C}, \mathrm{Mo}, \mathrm{Zr}$, and $\mathrm{Cr}$ obtained at different irradiation doses (0/1.0/20.0 dpa).

As shown in Figure $7 \mathrm{a}, \mathrm{C}, \mathrm{Zr}, \mathrm{Mo}$, and the molecular ions of $\mathrm{ZrN}^{+}$are segregated, while the homogeneous distribution of $\mathrm{Cr}$ is observed. Moreover, the segregations of $\mathrm{C}, \mathrm{Zr}$, $\mathrm{N}$, and Mo are located in the same position, indicating the formation of nano-sized $(\mathrm{Zr}, \mathrm{Mo})$ $(C, N)$ precipitates. The research shows that Mo can improve performance of the second phases in the material [33]. For example, Mo can be incorporated as $\mathrm{MoC}$ into ( $\mathrm{Nb}, \mathrm{Mo})(\mathrm{C}$, $\mathrm{N}$ ) in microalloyed steel, reducing the driving force for coarsening of second phases [34]. Compared with $\mathrm{Nb}(\mathrm{C}, \mathrm{N})$ having no $\mathrm{Mo}$, the $(\mathrm{Nb}, \mathrm{Mo})(\mathrm{C}, \mathrm{N})$ nano-precipitates possess stronger pinning and strengthening ability. Similarly, $(\mathrm{Zr}, \mathrm{Mo})(\mathrm{C}, \mathrm{N})$, as the nano-sized precipitates with $\mathrm{Mo}$, can also provide a better strengthening effect for $\mathrm{FeCrAl}$ alloys. 
(a)

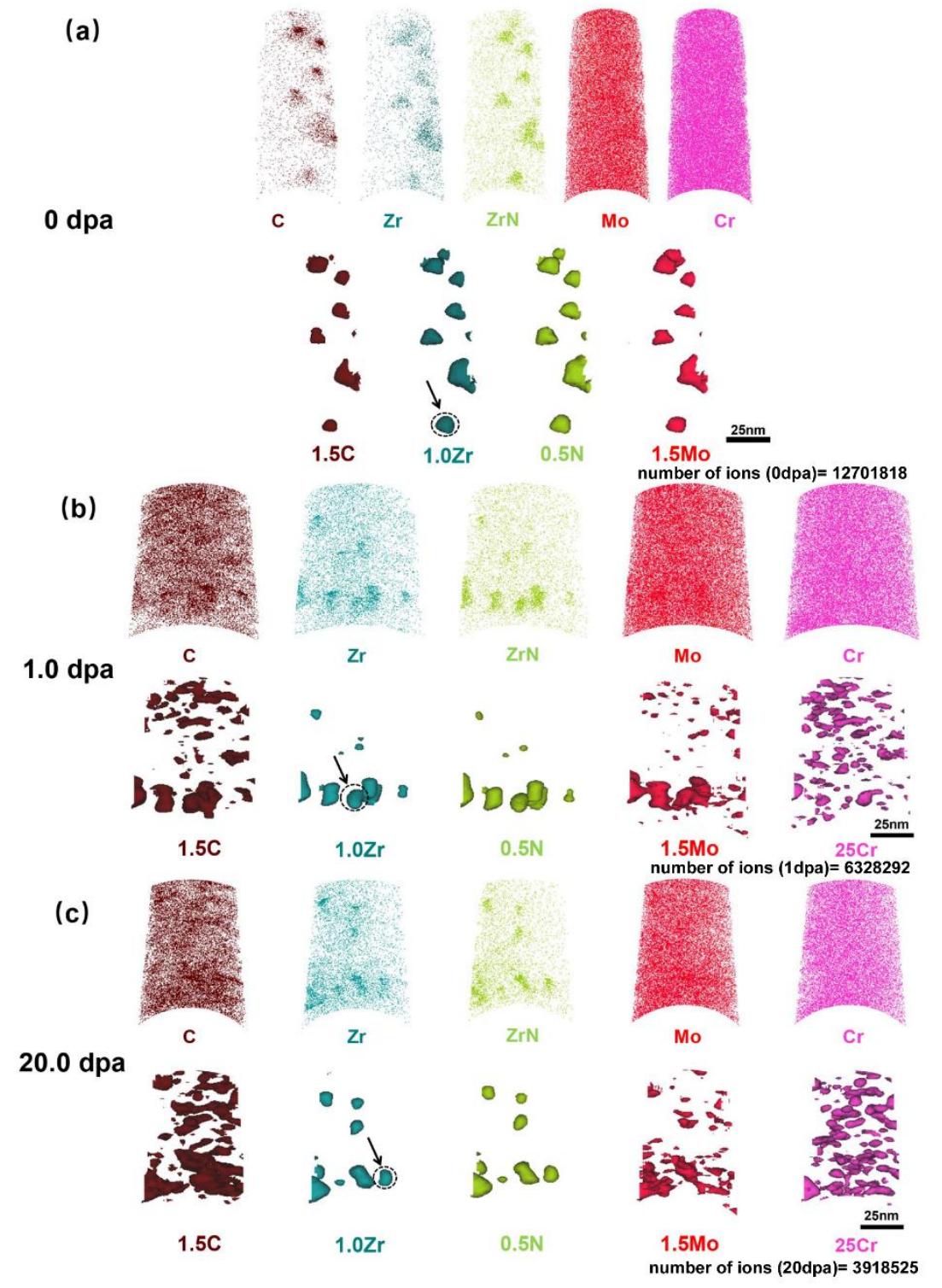

Figure 7. 3D distribution maps of $\mathrm{C}, \mathrm{Zr}, \mathrm{ZrN}^{+}, \mathrm{Mo}$, and $\mathrm{Cr}$, as well as the iso-concentration surfaces of 1.5 at \% C, 1.0 at $\% \mathrm{Zr}, 0.5$ at \% N, 1.5 at \% Mo, and 25 at \% Cr, at different irradiation doses measured by APT: (a) $0 \mathrm{dpa}$, (b) $1.0 \mathrm{dpa}$, and (c) $20.0 \mathrm{dpa}$. Since the $\mathrm{Cr}$ is distributed homogeneously in the unirradiated specimen, it is not necessary to make iso-concentration surfaces of $\mathrm{Cr}$. The three Zr-enriched domains in the dotted circle, indicated by the black arrow, will be separately selected for analysis later.

Based on the simulation of SRIM of specimens with a high irradiation dose $\left(1.27 \times 10^{16} \mathrm{Fe}^{+} / \mathrm{cm}^{2}\right)$, the two different regions, which are a low damage region $(\sim 1 \mathrm{dpa})$ and a high damage region ( $20 \mathrm{dpa})$, are intercepted and analyzed by APT, respectively (Figure $7 b, c)$. It can be seen from Figure $7 b, c$ that, compared with the APT results of nonirradiated specimens, the enrichment positions of $\mathrm{Mo}$ and $\mathrm{Zr}$ in the $\mathrm{Zr}$-enriched domains no longer completely coincide, and a huge count of tiny Mo-enriched domains are present in the matrix. In addition to the coincidence of $C$ with the enrichment position of $\mathrm{Zr}$, there are also high-density and nano-sized C-enriched domains in the matrix, which correspond to the position of the Mo-enriched domains. The segregation of $\mathrm{N}$ and $\mathrm{Zr}$ are unchanged and there is no new segregation in the matrix. Moreover, fine, spherical $\mathrm{Cr}$-enriched clusters with high number density, regarding the $\alpha^{\prime}$ phase, are generated due to the degree of rising spinodal decomposition induced by irradiation $[14,35,36]$. 
The diameter $(d)$ and number density $(N)$ of various secondary phases at different irradiation doses were calculated (Table 3). In this experiment, the Zr-enriched domain, Mo-enriched domain, and $\mathrm{Cr}$-enriched domain represent $(\mathrm{Zr}, \mathrm{Mo})(\mathrm{C}, \mathrm{N}), \mathrm{MoC}$, and $\alpha^{\prime}$ phase, respectively. When calculating the $d$ and $N$ of MoC, Mo-enriched domains with the same segregation position as $\mathrm{Zr}$-enriched domains were excluded. However, it must be mentioned that the existence of local magnification affects results in the precipitates' size, obtained by APT, to appear slightly larger than the actual size [37,38]. It can be seen from Table 2 that, with the increase in irradiation damage, the $d$ of $(\mathrm{Zr}, \mathrm{Mo})(\mathrm{C}, \mathrm{N})$ decreases slightly and the $N$ remains unchanged. The $d$ of MoC increases and the $N$ has no change. The $d$ of the $\alpha^{\prime}$ phase does not change significantly and the $N$ increases.

Table 3. The diameter $(d)$ and number density $(N)$ of precipitates in different irradiation doses.

\begin{tabular}{ccc}
\hline Type of Precipitate & $\mathbf{d} / \mathbf{n m}$ & $\mathrm{N} / \times \mathbf{1 0}^{\mathbf{2 2}} \mathbf{~}^{-\mathbf{3}}$ \\
\hline$(\mathrm{Zr}, \mathrm{Mo})(\mathrm{C}, \mathrm{N})(0 \mathrm{dpa})$ & $5.6 \pm 1.1$ & 4.1 \\
$(\mathrm{Zr}, \mathrm{Mo})(\mathrm{C}, \mathrm{N})(1.0 \mathrm{dpa})$ & $5.0 \pm 2.0$ & 5.1 \\
$(\mathrm{Zr}, \mathrm{Mo})(\mathrm{C}, \mathrm{N})(20.0 \mathrm{dpa})$ & $4.6 \pm 1.2$ & 4.6 \\
MoC $(1.0 \mathrm{dpa})$ & $1.8 \pm 0.5$ & 30.4 \\
MoC $(20.0 \mathrm{dpa})$ & $3.2 \pm 0.7$ & 29.7 \\
$\alpha^{\prime}$ phase $(1.0 \mathrm{dpa})$ & $1.7 \pm 0.3$ & 164.3 \\
$\alpha^{\prime}$ phase $(20.0 \mathrm{dpa})$ & $1.8 \pm 0.4$ & 201.1 \\
\hline
\end{tabular}

The formation of $\mathrm{MoC}$ and $\alpha^{\prime}$ phase is one of the reasons for irradiation hardening of materials. To quantify the contribution of precipitation to material hardening, the dispersed-barrier hardening (DBH) (Equation (2)) model was used to calculate the strength increment $\Delta \sigma_{y}$ caused by nano-precipitates.

$$
\Delta \sigma_{y}=f(N, d)=\alpha M G b \sqrt{N d}
$$

where $\alpha$ is the barrier strength of nano-precipitates taken as $0.048 \pm 0.012\left(\alpha^{\prime}\right.$ phase) and $0.27 \pm 0.06$ (MoC) [22,39], $M$ is the Taylor factor ( 3.06 for bcc Fe-based materials) [40], $b$ is the Burgers vector $(\sim 0.228 \mathrm{~nm})$, and $G$ is the shear modulus ( 82.2 GPa) [41]. The terms $d$ and $N$ represent mean diameter and number density of nano-precipitates, respectively.

The increase in strength associated with precipitates induced by irradiation can be calculated by linear-superposition Equation (3) as follows [39]:

$$
\Delta \sigma_{y}=f\left(N_{\alpha^{\prime}}, d_{\alpha^{\prime}}\right)+f\left(N_{M o C}, d_{M o C}\right)
$$

The increment of strength $\left(\Delta \sigma_{y}\right)$ can be converted to the increment of hardness $\left(\Delta H_{n}\right)$ by using the Rice equation [42] as follows:

$$
\Delta H_{n}=\Delta \sigma_{y} / 0.274
$$

Based on the above calculations, and ignoring the hardening of pure Fe caused by irradiation, the experimental and calculative data obtained for contributions from the hardness effects for the formation of $\mathrm{MoC}$ and $\alpha^{\prime}$ phase under irradiation at different doses are summarized in Figure 8 . The calculated value of hardness $\left(\Delta H_{\text {cal }}\right)$ is $1.10 \mathrm{GPa}$ at $1.0 \mathrm{dpa}$, which is accordant with the experimental data. Nevertheless, the $\Delta H_{c a l}$. is $1.41 \mathrm{GPa}$ at $20.0 \mathrm{dpa}$, which is lower than the corresponding experimental value. The reason for this phenomenon is the formation of loops with high density induced by high irradiation dose, and all of these loops make significant contributions to hardening. The reason corresponds to the TEM results in Figure 2. 


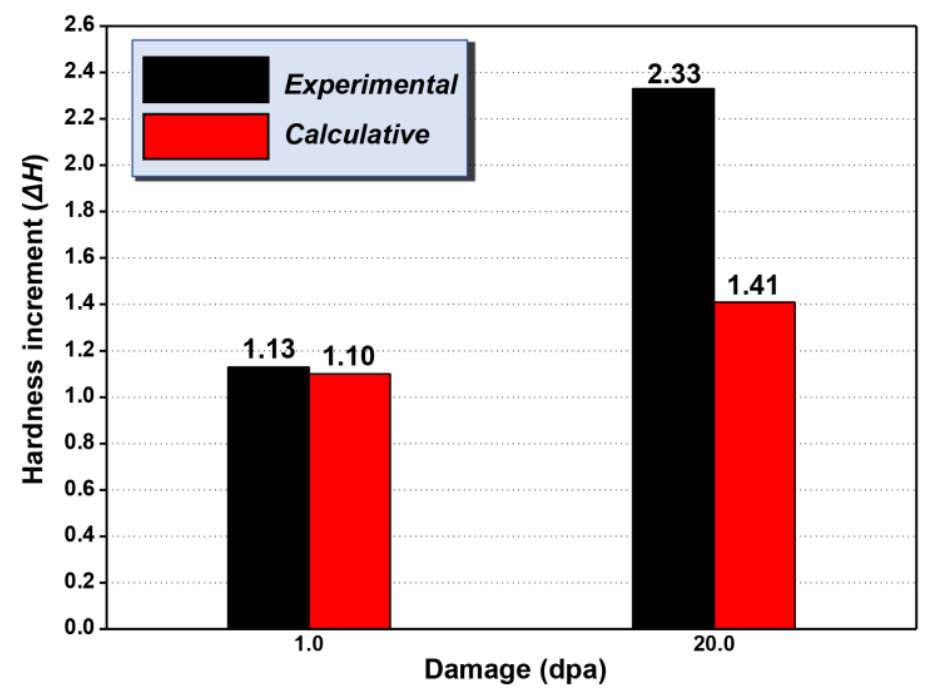

Figure 8. Schematic diagram of the radiation-induced hardness increment $(\Delta H)$ in the experiment (black) and calculation (red) at the damage dose of $1.0 \mathrm{dpa}$ and $20.0 \mathrm{dpa}$, respectively.

The chemical composition of strengthening precipitate $(\mathrm{Zr}, \mathrm{Mo})(\mathrm{C}, \mathrm{N})$ at different irradiation doses was measured by APT. Single $(\mathrm{Zr}, \mathrm{Mo})(\mathrm{C}, \mathrm{N})$ precipitates indicated by the black arrow in Figure 7 were selected for one-dimensional concentration distribution analysis (Figure 9). It must be noted that the composition of all ( $\mathrm{Zr}, \mathrm{Mo})(\mathrm{C}, \mathrm{N})$ precipitates in specimens at different irradiation doses is roughly the same, so a single precipitate selected can represent all of them in the one specimen. It can be found that the enrichment of Mo is the same as that of $C, Z r$, and $N$ in $(\mathrm{Zr}, \mathrm{Mo})(\mathrm{C}, \mathrm{N})$, though it is not enriched in the outer layer of the particle, which is different from the results of some other studies $[43,44]$. This indicates that the presence of $\mathrm{Mo}$ in $(\mathrm{Zr}, \mathrm{Mo})(\mathrm{C}, \mathrm{N})$ does not inhibit the coarsening of the second phase by blocking the diffusion of elements to the second phase through the formation of a Mo-enriched layer. According to the APT results, it is speculated that Mo doped into the precipitates as MoC and reduced the surface energy of the secondary phase/matrix, thus reducing the driving force of the coarsening of the secondary phase, which is similar to the research results of Enloe et al. [34].

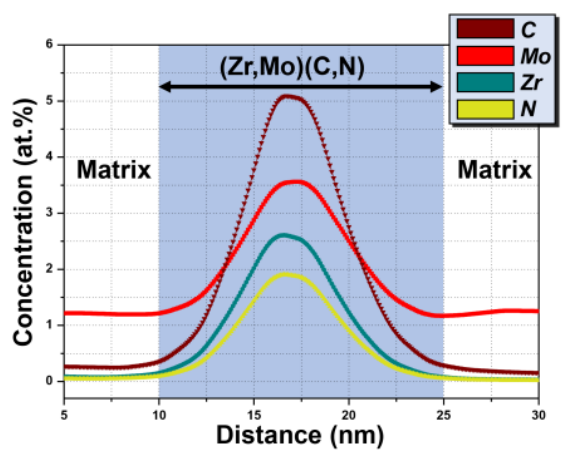

(a)

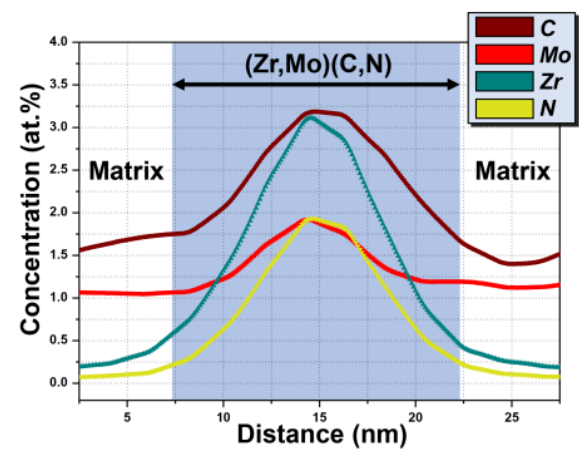

(b)

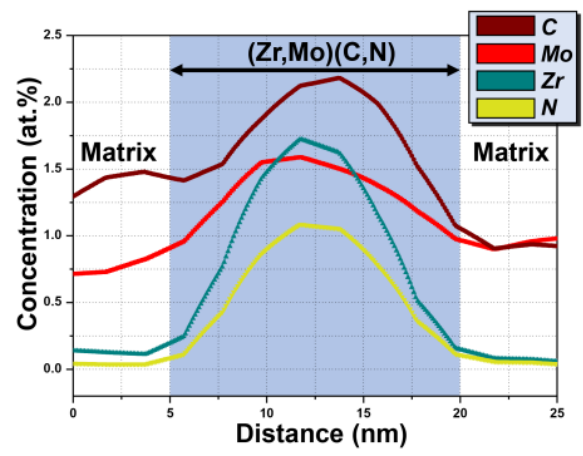

(c)

Figure 9. $1 \mathrm{D}$ concentration distribution of $\mathrm{C}, \mathrm{Mo}$, and $\mathrm{Zr}$ atoms corresponding to a single $(\mathrm{Zr}, \mathrm{Mo})(\mathrm{C}, \mathrm{N})$ particle, indicated by the black arrow at different irradiation dose specimens (a) $0 \mathrm{dpa}$, (b) $1.0 \mathrm{dpa}$, and (c) $20.0 \mathrm{dpa}$, respectively.

In addition, with the increase in damage, the proportion of different elements in $(\mathrm{Zr}$, Mo) $(\mathrm{C}, \mathrm{N})$ precipitates changes.

As we can see in Figure 9, the contents of $\mathrm{Zr}, \mathrm{Mo}, \mathrm{C}$, and $\mathrm{N}$ in the precipitates are too low to be practical. This is because the existence of trajectory aberrations caused by local magnification effects results in a large amount of Fe and $\mathrm{Cr}$ being introduced into ( $\mathrm{Zr}, \mathrm{Mo}$ ) 
$(\mathrm{C}, \mathrm{N})[37,38]$. Hence, all Fe and $\mathrm{Cr}$ in $(\mathrm{Zr}, \mathrm{Mo})(\mathrm{C}, \mathrm{N})$ were removed, while $\mathrm{Zr}, \mathrm{Mo}, \mathrm{C}$, and $\mathrm{N}$ were reserved during the progress of calculation. The proportion of the four elements in $(\mathrm{Zr}, \mathrm{Mo})(\mathrm{C}, \mathrm{N})$ was calculated and the peak proportions of each element are listed in Table 3.

It can be seen in Table 4 that, before irradiation, the peak proportions of $\mathrm{C}$, Mo, $\mathrm{Zr}$, and $\mathrm{N}$ in $(\mathrm{Zr}, \mathrm{Mo})(\mathrm{C}, \mathrm{N})$ are $38.7 \%, 27.1 \%, 19.8 \%$, and $14.4 \%$, respectively. When the irradiation dose is $1.0 \mathrm{dpa}$, the peak proportions of $\mathrm{C}, \mathrm{Mo}, \mathrm{Zr}$, and $\mathrm{N}$ in the $(\mathrm{Zr}, \mathrm{Mo})(\mathrm{C}, \mathrm{N})$ are $33.2 \%$, $24.2 \%, 26.2 \%$, and $16.4 \%$, respectively, and the proportions of $C$ and Mo in the precipitates decrease significantly. When the irradiation dose is $20.0 \mathrm{dpa}$, the peak proportions of $\mathrm{C}$, $\mathrm{Mo}, \mathrm{Zr}$, and $\mathrm{N}$ in the $\mathrm{Zr}, \mathrm{Mo})(\mathrm{C}, \mathrm{N})$ are $31.2 \%, 18.8 \%, 31.1 \%$, and $18.9 \%$, respectively. The peak proportions of $\mathrm{C}$ and $\mathrm{Mo}$ in the $(\mathrm{Zr}, \mathrm{Mo})(\mathrm{C}, \mathrm{N})$ continue to decline.

Table 4. Peak proportions of $\mathrm{C}, \mathrm{Mo}, \mathrm{N}$, and $\mathrm{Zr}$ in $(\mathrm{Zr}, \mathrm{Mo})(\mathrm{C}, \mathrm{N})$ with different irradiation doses.

\begin{tabular}{cccccc}
\hline \multirow{2}{*}{ dpa } & C & Mo & Zr & N \\
\cline { 2 - 5 } & \multicolumn{3}{c}{ at $\%$} \\
0 & 38.7 & 27.1 & & 19.8 & 14.4 \\
1 & 33.2 & 24.2 & 26.2 & 16.4 \\
20 & 31.2 & 18.8 & 31.1 & 18.9 \\
\hline
\end{tabular}

The ratio of $(\mathrm{Zr}+\mathrm{Mo}) /(\mathrm{C}+\mathrm{N})$ in $(\mathrm{Zr}, \mathrm{Mo})(\mathrm{C}, \mathrm{N})$ is roughly 1:1. Therefore, $(\mathrm{Zr}, \mathrm{Mo})(\mathrm{C}$, $\mathrm{N})$ could be seen as the complex of $\mathrm{ZrC}, \mathrm{ZrN}$, and MoC. The absolute value of molar free energy of formation of $\operatorname{ZrC}\left(\Delta G_{298}=-193.3 \mathrm{~kJ} \mathrm{~mol}^{-1}\right)$ and $\operatorname{ZrN}\left(\Delta G_{298}=-336.7 \mathrm{~kJ} \mathrm{~mol}^{-1}\right)$ is much higher than the molar free energy of formation of $\mathrm{MoC}\left(\Delta G_{298}=-10.0 \mathrm{~kJ} \cdot \mathrm{mol}^{-1}\right)$. In addition, the melting points of $\mathrm{ZrC}\left(\sim 3532^{\circ} \mathrm{C}\right)$ and $\mathrm{ZrN}\left(\sim 2952{ }^{\circ} \mathrm{C}\right)$ are also much higher than that of $\mathrm{MoC}\left(\sim 2700{ }^{\circ} \mathrm{C}\right)$, indicating that $\mathrm{ZrC}$ and $\mathrm{ZrN}$ are more stable than MoC. Therefore, irradiation causes $\mathrm{MoC}$ in $(\mathrm{Zr}, \mathrm{Mo})(\mathrm{C}, \mathrm{N})$ to decompose, resulting in a decrease in the contents of Mo and $\mathrm{C}$. With the increase in irradiation damage, the cascade collision increases, resulting in more MoC decomposition in $(\mathrm{Zr}, \mathrm{Mo})(\mathrm{C}, \mathrm{N})$. Therefore, the specific gravity of Mo and $C$ further decreases, resulting in the size of $(\mathrm{Zr}, \mathrm{Mo})(\mathrm{C}, \mathrm{N})$ trending down, which is consistent with the results in Table 4.

The reduction of Mo and $\mathrm{C}$ in $(\mathrm{Zr}, \mathrm{Mo})(\mathrm{C}, \mathrm{N})$ would result in the decline of its anticoarsening ability. Several studies have described that coarsening will occur under the working environment of high temperature and weaken the pinning effect of precipitates for grain boundaries and dislocations, resulting in deterioration of the high temperature properties and anti-irradiation properties of the material $[45,46]$. With the increase in irradiation damage, more $\mathrm{Mo}$ and $\mathrm{C}$ in $(\mathrm{Zr}, \mathrm{Mo})(\mathrm{C}, \mathrm{N})$ diffuse and segregate at the interface of MoC, resulting in an increase in MoC precipitate size, which is also consistent with the results in Table 4.

\section{Conclusions}

Nanoindentation, TEM, and APT were utilized to study the effects of irradiation dose on the microstructure and mechanical properties of FeCrAl-1.5wt.\% ZrC alloys. The conclusions of this work can be summarized as follows:

1. Fe-ions irradiation results in significant hardening of FeCrAl-1.5wt.\% ZrC alloys. Compared with the $5.68 \mathrm{GPa}$ hardness of an unirradiated specimen, the hardness of an irradiated specimen with a 1.0 dpa irradiation dose increases to $6.81 \mathrm{GPa}$, an increase of $19.9 \%$. When the irradiation dose increases 20 times, from $1.0 \mathrm{dpa}$ to $20.0 \mathrm{dpa}$, and the hardness increases from 6.81 to $8.01 \mathrm{GPa}$, an increase of only $17.6 \%$. The increasing rate of hardness is much lower than that from unirradiated to an irradiation dose of $1.0 \mathrm{dpa}$, indicating that, with the increase in damage, the hardening of the specimen tends toward saturation.

2. When the irradiation dose is $1.0 \mathrm{dpa}$, the hardening of the material is mainly caused by nano-precipitates induced by irradiation, such as $\alpha^{\prime}$ phase and MoC precipitates. 
When the irradiation dose is $20.0 \mathrm{dpa}$, the dislocation loops and nano-precipitates induced by irradiation also occur and, together, lead to increased material hardness. 3. The Fe-ions irradiation enhances the diffusion of $\mathrm{Mo}$ and $\mathrm{C}$ in $(\mathrm{Zr}, \mathrm{Mo})(\mathrm{C}, \mathrm{N})$. With the increase in irradiation, the proportion of Mo and $C$ in $(\mathrm{Zr}, \mathrm{Mo})(\mathrm{C}, \mathrm{N})$ decreases, the size of $(\mathrm{Zr}, \mathrm{Mo})(\mathrm{C}, \mathrm{N})$ decreases, and the size of MoC increases.

Author Contributions: R.W.: investigation, conceptualization, methodology, formal analysis, writing-original draft, writing-review and editing. H.W.: investigation, conceptualization, funding acquisition, data curation, formal analysis, writing-review and editing. X.Z.: investigation, writing-review and editing. X.L.: investigation, data curation. Y.L.: investigation, data curation. Y.G.: investigation, data curation. X.A.: investigation, data curation. W.L.: investigation, conceptualization, funding acquisition, data curation, formal analysis, writing-review and editing, supervision. All authors have read and agreed to the published version of the manuscript.

Funding: This work was supported by the National Natural Science Foundation of China (NSFC) [Grant No. 51971207].

Institutional Review Board Statement: Not applicable.

Informed Consent Statement: Not applicable.

Data Availability Statement: Data underlying the results presented in this paper are not publicly available at this time but may be obtained from the authors upon reasonable request.

Conflicts of Interest: The authors declare no conflict of interest.

\section{Appendix A}

Nearest Neighbor Distribution (NND) curves were used to determine and calibrate the $d_{\max }$ of different precipitates at different irradiation doses. Firstly, we determined the value of $d_{\max }$ by the intersection of an NND curve. The right intersections of these four groups of curves are 3.2, 2.6, 1.6, and 0.7, respectively, as shown in Figure A1. Secondly, these four values were substituted into "Size Distribution", respectively, and four new groups of curves were obtained, as shown in Figure A2. The value of the intersection of the red line and the $\mathrm{X}$ axis is $N_{\min }$ and the $N_{\min }$ of the four precipitates is determined as 50,45 , 40 , and 12, respectively. Finally, the values of $L$ and $d_{\text {erosion }}$ remain the same as that of $d_{\max }$. All parameter values are listed in Table 1 in Section 2 (Experimental Procedures). Through the determination and calibration of these parameters, more accurate cluster information can be obtained, including size, quantity, density, and so on. 


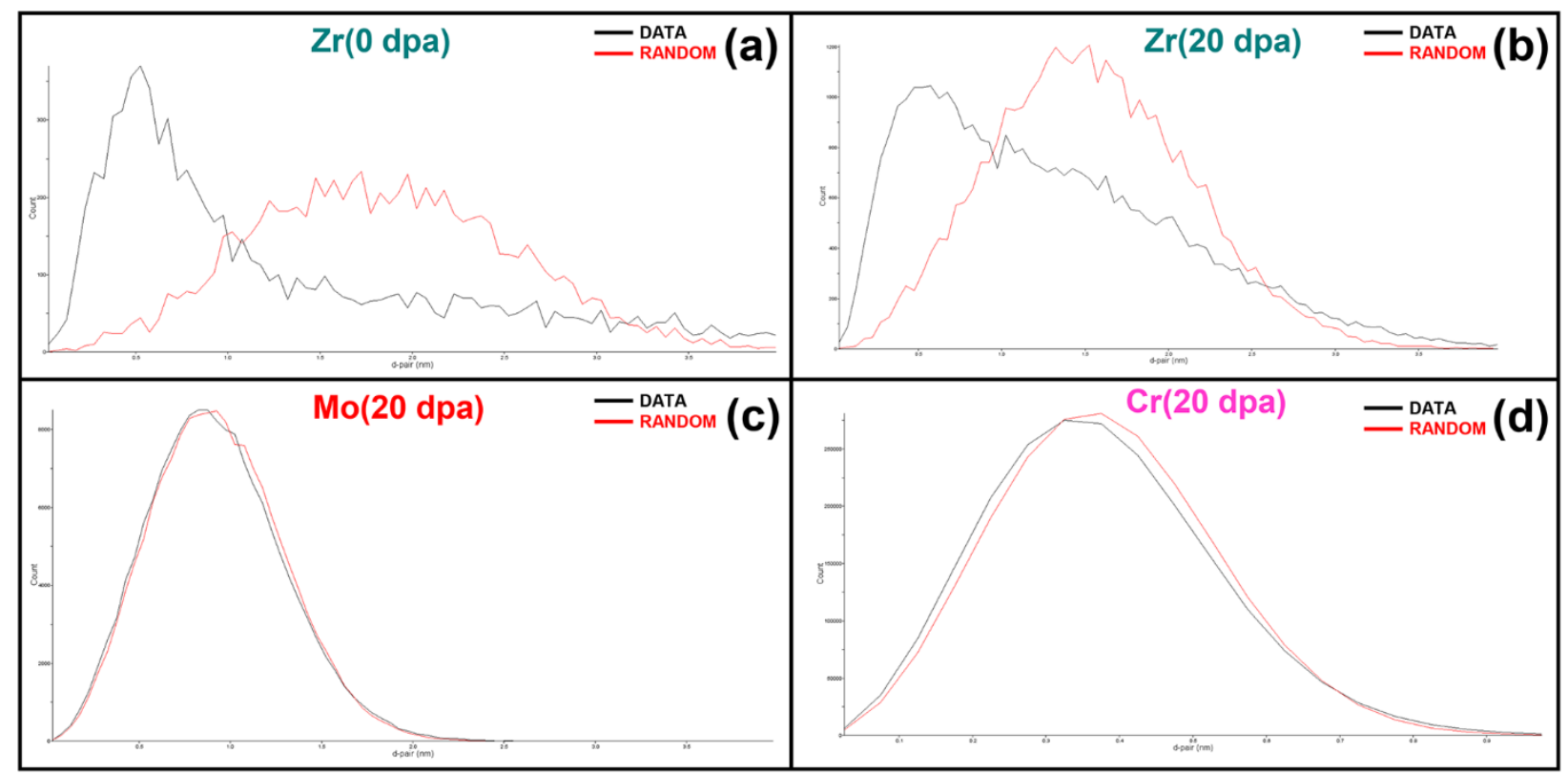

Figure A1. NND analyses of (a) Zr at 0 dpa, (b) Zr at 20 dpa, (c) Mo at $20 \mathrm{dpa}$, and (d) Cr at $20 \mathrm{dpa}$.

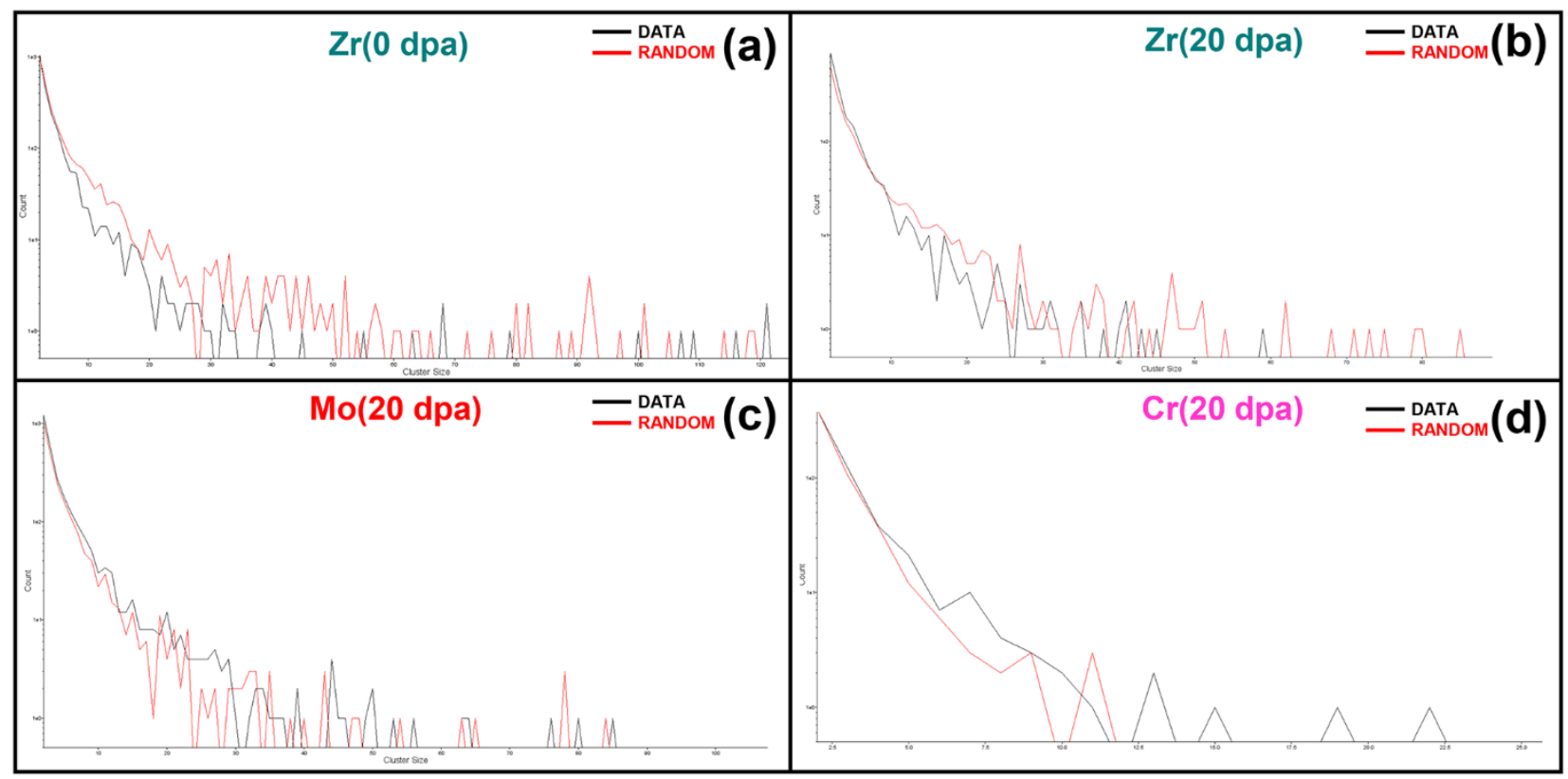

Figure A2. Size distribution analyses of (a) Zr at $0 \mathrm{dpa}$, (b) Zr at $20 \mathrm{dpa}$, (c) Mo at $20 \mathrm{dpa}$, and (d) Cr at $20 \mathrm{dpa}$.

\section{References}

1. Hu, W.; Dong, Z.; Wang, H.; Ahamad, T.; Ma, Z. Microstructure refinement and mechanical properties improvement in the W-Y2O3 alloys via optimized freeze-drying. Int. J. Refract. Met. Hard Mater. 2021, 95, 105453. [CrossRef]

2. Sun, H.; Wang, H.; He, X.; Wang, F.; An, X.; Wang, Z. Study on high temperature creep behavior of the accident-resistant cladding Fe-13Cr-4Al-1.85Mo-0.85Nb alloy. Mater. Sci. Eng. A 2021, 802, 140688. [CrossRef]

3. Zhang, Y.; He, H.; Wang, H.; Chen, G.; An, X.; Wang, Y. Evolution of microstructure and mechanical properties of 9Cr ferrite/martensite steels with different $\mathrm{Si}$ content after long-term aging at $550{ }^{\circ} \mathrm{C}$. J. Alloy. Compd. 2021, 873, 159817. [CrossRef]

4. Chen, L.; Huang, X.; He, K.; Wang, H. Precipitation behavior and age hardening effect of the precipitates in a Fe-13Cr-4Al-2Mo1.2Nb alloy. Mater. Charact. 2021, 173, 110918. [CrossRef]

5. Zhang, Y.; Wang, H.; An, X.; Chen, G.; Sun, H.; Wang, Y. Dynamic strain aging behavior of accident tolerance fuel cladding FeCrAl-based alloy for advanced nuclear energy. J. Mater. Sci. 2021, 56, 8815-8834. [CrossRef]

6. Liu, W.; Li, Q.; Zhou, B.; Yan, Q.; Yao, M. Effect of heat treatment on the microstructure and corrosion resistance of a Zr-Sn-NbFe-Cr alloy. J. Nucl. Mater. 2005, 341, 97-102. [CrossRef] 
7. Park, D.J.; Kim, H.G.; Park, J.Y.; Jung, Y.I.; Park, J.H.; Koo, Y.H. A study of the oxidation of FeCrAl alloy in pressurized water and high-temperature steam environment. Corros. Sci. 2015, 94, 459-465. [CrossRef]

8. Terrani, K.A.; Parish, C.M.; Shin, D.; Pint, B.A. Protection of zirconium by alumina- and chromia-forming iron alloys under high-temperature steam exposure. J. Nucl. Mater. 2013, 438, 64-71. [CrossRef]

9. George, N.M.; Terrani, K.; Powers, J.; Worrall, A.; Maldonado, I. Neutronic analysis of candidate accident-tolerant cladding concepts in pressurized water reactors. Ann. Nucl. Energy 2015, 75, 703-712. [CrossRef]

10. Bachhav, M.; Yao, L.; Robert Odette, G.; Marquis, E.A. Microstructural changes in a neutron-irradiated Fe-6 at.\%Cr alloy. J. Nucl. Mater. 2014, 453, 334-339. [CrossRef]

11. Field, K.G.; Gussev, M.N.; Yamamoto, Y.; Snead, L.L. Deformation behavior of laser welds in high temperature oxidation resistant $\mathrm{Fe}-\mathrm{Cr}-\mathrm{Al}$ alloys for fuel cladding applications. J. Nucl. Mater. 2014, 454, 352-358. [CrossRef]

12. Terrani, K.A.; Zinkle, S.J.; Snead, L.L. Advanced oxidation-resistant iron-based alloys for LWR fuel cladding. J. Nucl. Mater. 2014, 448, 420-435. [CrossRef]

13. Edmondson, P.D.; Briggs, S.A.; Yamamoto, Y.; Howard, R.H.; Sridharan, K.; Terrani, K.A.; Field, K.G. Irradiation-enhanced $\alpha^{\prime}$ precipitation in model FeCrAl alloys. Scr. Mater. 2016, 116, 112-116. [CrossRef]

14. Sickafus, K.E.; Grimes, R.W.; Valdez, J.A.; Cleave, A.; Tang, M.; Ishimaru, M.; Corish, S.M.; Stanek, C.R.; Uberuaga, B.P. Radiationinduced amorphization resistance and radiation tolerance in structurally related oxides. Nat. Mater. 2007, 6, 217-223. [CrossRef] [PubMed]

15. Field, K.G.; Briggs, S.A.; Hu, X.; Yamamoto, Y.; Howard, R.H.; Sridharan, K. Heterogeneous dislocation loop formation near grain boundaries in a neutron-irradiated commercial FeCrAl alloy. J. Nucl. Mater. 2017, 483, 54-61. [CrossRef]

16. Gussev, M.N.; Field, K.G.; Yamamoto, Y. Design, properties, and weldability of advanced oxidation-resistant FeCrAl alloys. Mater. Des. 2017, 129, 227-238. [CrossRef]

17. Yutani, K.; Kishimoto, H.; Kasada, R.; Kimura, A. Evaluation of Helium effects on swelling behavior of oxide dispersion strengthened ferritic steels under ion irradiation. J. Nucl. Mater. 2007, 367-370, 423-427. [CrossRef]

18. Ackland, G. Materials science. Controlling radiation damage. Science 2010, 327, 1587-1588. [CrossRef] [PubMed]

19. Zhao, Q.; Qiao, Z.; Liu, Y.; Yu, L.; Huang, Y.; Guo, Q.; Li, H. Characterization of 14Cr ODS Steel Fabricated by Spark Plasma Sintering. Metals 2019, 9, 200. [CrossRef]

20. Shibata, H.; Ukai, S.; Oono, N.H.; Sakamoto, K.; Hirai, M. Development of accident tolerant FeCrAl-ODS steels utilizing Ce-oxide particles dispersion. J. Nucl. Mater. 2018, 502, 228-235. [CrossRef]

21. Gao, R.; Xia, L.L.; Zhang, T.; Wang, X.P.; Fang, Q.F.; Liu, C.S. Oxidation resistance in LBE and air and tensile properties of ODS ferritic steels containing Al/Zr elements. J. Nucl. Mater. 2014, 455, 407-411. [CrossRef]

22. Wang, R.; Wang, H.; Zhu, X.; Liang, X.; Li, Y.; Liu, W. Evolution of microstructure and mechanical properties of ZrC reinforced FeCrAl alloy after Fe-ions irradiation. J. Nucl. Mater. 2021, 557, 153243. [CrossRef]

23. Ding, R.; Wang, H.; Jiang, Y.; Liu, R.; Jing, K.; Sun, M.; Zhang, R.; Qiu, S.; Xie, Z.; Deng, H.; et al. Effects of ZrC addition on the microstructure and mechanical properties of $\mathrm{Fe}-\mathrm{Cr}-\mathrm{Al}$ alloys fabricated by spark plasma sintering. J. Alloy. Compd. 2019, 805, 1025-1033. [CrossRef]

24. Wan, H.; An, X.; Kong, Q.; Wu, X.; Feng, W.; Wang, H.; Wu, J.; Lu, C.; Zha, W.; Sun, H.; et al. Fabrication of ultrafine grained FeCrAl-0.6 wt.\% ZrC alloys with enhanced mechanical properties by spark plasma sintering. Adv. Powder Technol. 2021, 32, 1380-1389. [CrossRef]

25. Miller, M.K.; Russell, K.F.; Thompson, G.B. Strategies for fabricating atom probe specimens with a dual beam FIB. Ultramicroscopy 2005, 102, 287-298. [CrossRef]

26. Chen, H.; Cheng, Y.; Lin, C.; Peng, J.; Liang, X.; Gao, J.; Liu, W.; Huang, H. In-situ TEM observation of nanobubbles evolution in helium-irradiated aluminium upon tensile stressing. J. Nucl. Mater. 2019, 520, 178-184. [CrossRef]

27. Hosemann, P.; Kiener, D.; Wang, Y.; Maloy, S.A. Issues to consider using nano indentation on shallow ion beam irradiated materials. J. Nucl. Mater. 2012, 425, 136-139. [CrossRef]

28. Li, S.; Wang, Y.; Dai, X.; Liu, F.; Li, J.; Wang, X. Evaluation of hardening behaviors in ion-irradiated Fe-9Cr and Fe-20Cr alloys by nanoindentation technique. J. Nucl. Mater. 2016, 478, 50-55. [CrossRef]

29. Liu, X.; Wang, R.; Ren, A.; Jiang, J.; Xu, C.; Huang, P.; Qian, W.; Wu, Y.; Zhang, C. Evaluation of radiation hardening in ion-irradiated Fe based alloys by nanoindentation. J. Nucl. Mater. 2014, 444, 1-6. [CrossRef]

30. Miyazawa, T.; Nagasaka, T.; Kasada, R.; Hishinuma, Y.; Muroga, T.; Watanabe, H.; Yamamoto, T.; Nogami, S.; Hatakeyama, M. Evaluation of irradiation hardening of ion-irradiated V-4Cr-4Ti and V-4Cr-4Ti-0.15Y alloys by nanoindentation techniques. J. Nucl. Mater. 2014, 455, 440-444. [CrossRef]

31. Nix, W.D.; Gao, H. Indentation size effects in crystalline materials: A law for strain gradient plasticity. J. Mech. Phys. Solids 1998, 46, 411-425. [CrossRef]

32. Kasada, R.; Takayama, Y.; Yabuuchi, K.; Kimura, A. A new approach to evaluate irradiation hardening of ion-irradiated ferritic alloys by nano-indentation techniques. Fusion Eng. Des. 2011, 86, 2658-2661. [CrossRef]

33. Wang, Z.; Sun, X.; Yang, Z.; Yong, Q.; Zhang, C.; Li, Z.; Weng, Y. Carbide precipitation in austenite of a Ti-Mo-containing low-carbon steel during stress relaxation. Mater. Sci. Eng. A 2013, 573, 84-91. [CrossRef]

34. Enloe, C.M.; Findley, K.O.; Parish, C.M.; Miller, M.K.; De Cooman, B.C.; Speer, J.G. Compositional evolution of microalloy carbonitrides in a Mo-bearing microalloyed steel. Scr. Mater. 2013, 68, 55-58. [CrossRef] 
35. Field, K.G.; Hu, X.; Littrell, K.C.; Yamamoto, Y.; Snead, L.L. Radiation tolerance of neutron-irradiated model Fe-Cr-Al alloys. J. Nucl. Mater. 2015, 465, 746-755. [CrossRef]

36. Soisson, F.; Jourdan, T. Radiation-accelerated precipitation in Fe-Cr alloys. Acta Mater. 2016, 103, 870-881. [CrossRef]

37. Vurpillot, F.; Bostel, A.; Blavette, D. Trajectory overlaps and local magnification in three-dimensional atom probe. Appl. Phys. Lett. 2000, 76, 3127-3129. [CrossRef]

38. De Geuser, F.; Lefebvre, W.; Danoix, F.; Vurpillot, F.; Forbord, B.; Blavette, D. An improved reconstruction procedure for the correction of local magnification effects in three-dimensional atom-probe. Surf. Interface Anal. 2007, 39, 268-272. [CrossRef]

39. Bergner, F.; Pareige, C.; Hernández-Mayoral, M.; Malerba, L.; Heintze, C. Application of a three-feature dispersed-barrier hardening model to neutron-irradiated Fe-Cr model alloys. J. Nucl. Mater. 2014, 448, 96-102. [CrossRef]

40. Yang, Y.; Kang, S.H.; Zhang, C.; Jang, J. Nanoindentation on an oxide dispersion strengthened steel and a ferritic/martensitic steel implanted with He ions. J. Nucl. Mater. 2014, 455, 325-329. [CrossRef]

41. Cui, Y.; Aydogan, E.; Gigax, J.G.; Wang, Y.; Misra, A.; Maloy, S.A.; Li, N. In Situ Micro-Pillar Compression to Examine RadiationInduced Hardening Mechanisms of FeCrAl Alloys. Acta Mater. 2021, 202, 255-265. [CrossRef]

42. Lei, J.; Ding, H.; Shu, G.G.; Wan, Q.M. Study on the mechanical properties evolution of A508-3 steel under proton irradiation. Nucl. Instrum. Methods Phys. Res. Sect. B Beam Interact. Mater. At. 2014, 338, 13-18. [CrossRef]

43. Yuan, S.Q.; Liang, G.L.; Zhang, X.J. Interaction between Elements Nb and Mo During Precipitation in Microalloyed Austenite. J. Iron Steel Res. Int. 2010, 17, 60-63. [CrossRef]

44. Uemori, R.; Chijiiwa, R.; Tamehiro, H.; Morikawa, H. AP-FIM study on the effect of Mo addition on microstructure in Ti-Nb steel. Appl. Surf. Sci. 1994, 76-77, 255-260. [CrossRef]

45. Sun, Z.; Bei, H.; Yamamoto, Y. Microstructural control of FeCrAl alloys using Mo and Nb additions. Mater. Charact. 2017, 132, 126-131. [CrossRef]

46. Shen, Q.; Xiong, X.; Li, T.; Chen, H.; Cheng, Y.; Liu, W. Effects of co-addition of Ni and Al on precipitation evolution and mechanical properties of Fe-Cu alloy. Mater. Sci. Eng. A 2018, 723, 279-286. [CrossRef] 